\title{
Exploration and Practice of Teaching Reform of Computer Public Courses in Colleges and Universities under Big Data Environment
}

\author{
Xiangbin Gao \\ Linyi University, Shandong 273400, China \\ gxb0715@126.com
}

\begin{abstract}
The 21 st century has fully transited to the computer information age, in order to meet the needs of various professions, to adapt to the pace of information society development, universities have generally opened computer public courses. Firstly, this paper analyzes the current situation of computer public course teaching in Colleges and Universities under the big data environment, and then focuses on the reform of computer public course teaching from the aspects of computer teaching mode, teaching content, teaching methods and teaching evaluation. Practice shows that there is a certain lag in the teaching of computer public course in Colleges and universities at this stage. The reform of computer public course by adopting diversified teaching mode is helpful to cultivate students'informationization ability to the greatest extent and improve the quality of computer teaching.
\end{abstract}

Keywords: big data; university computer teaching, diversified teaching mode, reform and practice.

\section{Introduction}

Computer information technology has been developed rapidly in the 21 st century, and can be seen in all industries the application of computer information technology. In order to promote the integration of teaching and social posts in Colleges and universities, and to cultivate the students'solid information-based ability, colleges and universities generally offer computer public course teaching. Large data is the product of the development of computer information technology to a certain stage, which is a general term for a class of information sets. In the era of the rapid development of computer information technology, the teaching of computer courses in Colleges and universities should be eliminated. How to reform and develop the teaching of computer courses in Colleges and Universities under the big data environment is a realistic problem to be solved. In order to realize the teaching goal of training comprehensive talents, universities have carried out the exploration of the reform of computer public course teaching. Among them, Yan'an University took the lead in combining the reform of computer teaching with the background of large data, and put forward the educational and teaching concept of "precise theory, emphasis on skills, promote application". It adopted diversified teaching mode, realized the innovation and progress of computer public course teaching, and achieved remarkable teaching results. In this paper, Yan'an University computer public course teaching reform as a practical case, combined with the author's own exploration and thinking, put forward some suggestions for college computer teaching reform, in order to provide some ideas for the reform of college computer public course teaching.

\section{Analysis of the Current Situation of Computer Public Course Teaching in Colleges and Universities}

\subsection{The Content of Computer Public Course is Loose and Obsolete, and the Teaching Quality is not High.}

As far as the teaching contents of computer public courses in most colleges and universities are concerned, there are some problems such as loose and obsolete teaching contents. The teaching of computer public courses in most colleges and universities is designed to cover a wide range of disciplines, including information, mathematics, electronics, communications and other disciplines, showing a strong comprehensive. However, in the process of choosing teaching content, teachers fail 
to clarify the key points of teaching and lack pertinence in making teaching plans, which leads to the loose content system of computer public course teaching. Due to the lack of close links between the teaching contents and the large span of knowledge, it is difficult for teachers to organize their courses. This is one of the reasons why the teaching quality of computer public courses is not high. Loose and obsolete knowledge system is easy to reduce students'enthusiasm for learning. In the information age, college students more or less come into contact with and master certain computer knowledge and skills. In this context, it is difficult for students to arouse their interest in public computer courses if the teaching content arranged by teachers remains "conservative" and divorced from practical application. Students'enthusiasm for this course is not high, leading to their knowledge learning is often in a half-informed state, which is not conducive to the application of computer skills for students.

\subsection{The Teaching Mode is Single, Which is not in Line with the Times.}

Teaching mode is the soul of teaching activities, and excellent teaching mode can help improve teaching quality. Comparing with foreign countries, our country's University Computer Public Course Teaching started late, teachers have not yet been able to form a systematic teaching model in the computer public course teaching, especially for non-computer majors, they are often in the "teacher classroom teaching - students on-line operation" teaching model. Learning computer knowledge in formula. This teaching mode is understandable, but it seems to be a single one. In this single teaching mode, students'interest in computer learning will inevitably be reduced, resulting in poor quality of computer teaching. In the large data environment, computer teaching should be more in line with the information society and the future jobs of students. This kind of teaching mode close to "dogma" is difficult to provide students with good learning opportunities (such as designing a complete computer project, simulating the actual environment to repair computers, according to needs). To write simple applications, etc.

\subsection{The Teaching Evaluation System is Lagging Behind, and the Evaluation Results are Difficult to Feedback and Guide Teaching.}

Teaching evaluation is the end and conclusion of teaching activities. Good teaching evaluation helps to find out the achievements and shortcomings of teaching activities, make up for the weaknesses and promote the improvement of teaching quality. However, after investigation, the author finds that there are obvious lags in the current evaluation system of computer public course teaching in universities, and there are mainly two evaluation systems. The first is to set the content of the computer grade examination, and arrange the students to do the corresponding operation and practice. Although this evaluation method is beyond reproach, it does exercise and improve students'basic computer operation skills, but the assignments set by teachers for the grade examination are divorced from the practical application, students know the corresponding computer operation knowledge, but it is difficult to apply knowledge transfer to life. The second is to arrange some simple assignments according to the content of the lesson to evaluate the students'mastery of knowledge. This teaching evaluation system is almost "nominal" and is difficult to play a corresponding role in evaluation. Because of the lag of the evaluation system of computer common course teaching, it is difficult to feedback and guide the teaching.

\section{Teaching Reform Strategy of Computer Public Courses based on Big Data Environment}

\subsection{Optimizing the Computer Public Course System based on Large Data Platform according to the Requirements of Computer Public Course Teaching in Colleges and Universities}

The reform of computer public curriculum in Colleges and universities should take the teaching requirements of computer courses as the starting point and construct a rigorous curriculum system with computer thinking according to the teaching objectives of computer courses. The author thinks that the computer public course can be divided into two parts to construct the curriculum system. The 
first part is the basic part, which arranges some computer theory knowledge and operation skills to train students'computer thinking and operation ability to meet the needs of students' study and work. This part of the computer curriculum system can also be called the "general knowledge" computer curriculum system. The second part is the interdisciplinary curriculum system of computer and students'professional knowledge, which is the improvement part of the computer public curriculum system. At this stage, all the specialties of higher education are closely related to computer knowledge, and the data processing and data analysis of some specialties need computers to be efficient and accurate. By promoting the integration of computer courses and professional courses, we can further cultivate and enhance students'comprehensive computer literacy so that they can operate computers flexibly to solve professional problems. For example, students majoring in language and history are instructed to use computer database technology to collect, search and retrieve professional documents; students majoring in bioengineering and economics are instructed to use computer software to analyze and process data; students majoring in information technology are instructed to use computer language to compile corresponding departments Unified procedures to solve professional problems. At the same time, relying on the large data platform, we can make and upload some excellent computer course resources to the computer cloud platform, and classify them according to "basic courses" and "improving courses". Students can choose the appropriate courses to study on the cloud platform according to their own needs.

\subsection{Based on the Three Major Learning Theories, Innovative and Diversified Teaching Mode.}

As mentioned above, teaching mode is the soul of teaching activities. In order to improve the teaching quality of computer public course, we need to eliminate the traditional single teaching mode and innovate the diversified teaching mode. Based on the three learning theories, this paper proposes a diversified teaching model. The so-called three learning theories are cognitive learning theory, behaviorism learning theory and constructivism learning theory. These three learning theories fully embody the concept of quality education, which regards students as the main body of teaching activities, teachers as the guide of students'learning, and pays attention to the exploration of students' subjective initiative in learning. Based on the three learning theories, the author constructs a diversified teaching mode as shown below.

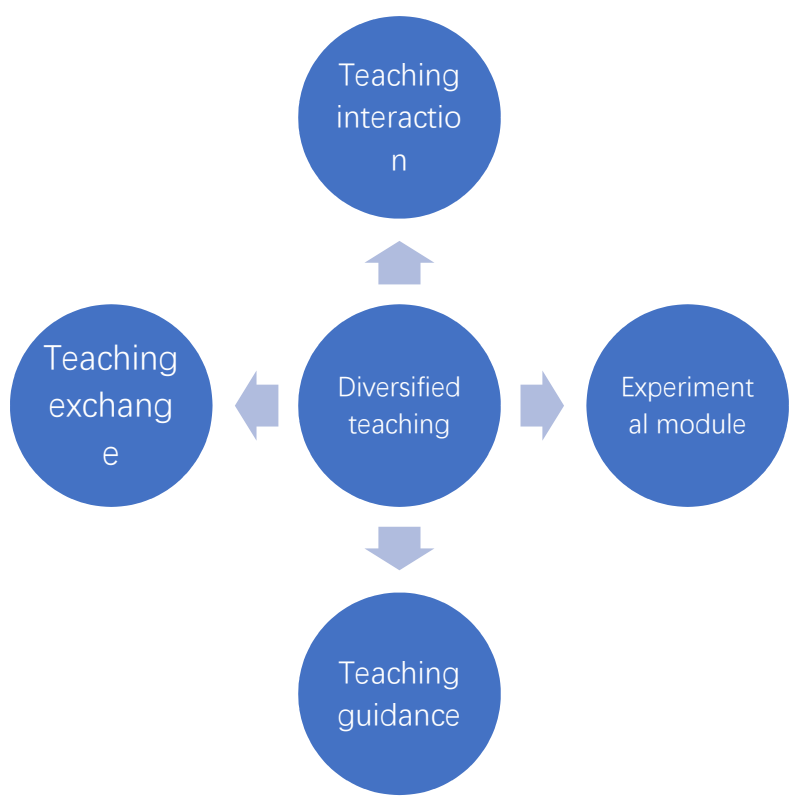

Fig 1. diversified teaching mode

There will be a diversified teaching atmosphere of four modules, each module can be designed separately corresponding teaching system. For example, in the interactive teaching module, the two- 
level teaching system of "participating in student discussion" and "feedback on students'homework" is designed; in the experimental module, the two-level teaching system of "designing experimental scheme" and "supervising experiment" is designed; in the teaching guidance module, the two-level teaching system of "guiding students' group study" and "guiding students'professional operation" is designed. In the teaching communication module, the two-level teaching system of "creating large data cloud platform to share resources" and "online and offline interactive communication" is designed.
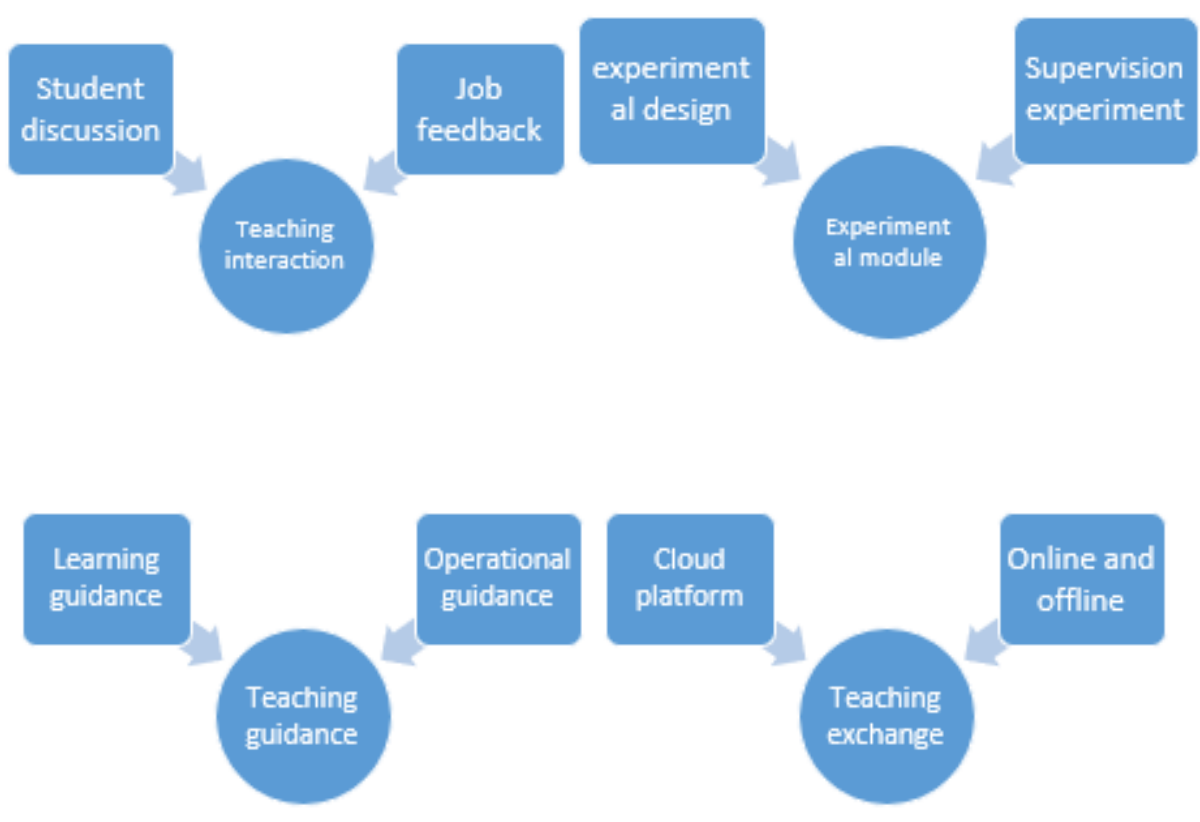

Fig 2. two level teaching system for each module

\subsection{Optimize Teaching Evaluation System.}

Teaching evaluation is an important basis for reflecting teaching results and improving teaching plans. The traditional teaching evaluation system is lagging behind and disconnected from the computer application in the large data environment. Therefore, it is necessary to optimize the teaching evaluation system of computer common courses. Specifically, teaching evaluation system can be designed from two aspects. Firstly, teachers evaluate the students'computer learning, rely on computer programs to assess the students' computer theoretical knowledge and operational skills, and can set up assessment methods according to the relevant provisions of computer grade examination. Secondly, students can evaluate teachers'teaching activities (both online and offline). Students can point out the problems in teachers' teaching activities and put forward corresponding suggestions to help teachers further improve the teaching system.

\section{Summary}

To sum up, this paper first analyzes the problems existing in the teaching system of computer public course in Colleges and universities from three aspects: teaching content, teaching mode and evaluation system, and then puts forward the teaching strategies of optimizing the curriculum system, innovating diversified teaching mode and improving the evaluation system of computer public course. In the new era, the teaching of computer public courses in Colleges and universities should be in line with the big data environment, innovate teaching modes, improve teaching methods, take students'employment and development as the basis, and enhance their comprehensive computer literacy. 


\section{References}

[1]. Chen Kun. Big data and teaching reform of public basic courses in Colleges and universities, [J]. science and education guide, 2017 (7z).

[2]. Liu Rongting. Big Data and Analysis of Teaching Reform of Computer Public Basic Course in Colleges and Universities [J].Digital World, 2017 (12): 480-480.

[3]. Yan Qiuling, Yang Aimei and Si Haifang. Research on the Teaching Reform of Computer Public Course in Colleges and Universities in the Age of Big Data [J].Fujian Computer, 2016, 32 (7): 56-58.

[4]. long rock. Under the age of big data, computer teaching reform in Colleges and universities, [J]. technology, 2014 (20): 215-215.

[5]. Long Yan. Computer teaching reform in Colleges and universities in the era of big data, [J]. technology, 2014 (20): 215-215.

[6]. Yang Aiqin, Sun Ailing. Exploration of the Teaching Reform of the Basic Course of Computer Information Technology in University in the Age of Big Data[J]. Fujian Computer, 2016,32(12): 55-55. 